\title{
Hardfacing steel with nanostructured coatings of Stellite- 6 by supersonic laser deposition
}

\author{
Rocco Lupoi ${ }^{1}$, Andrew Cockburn ${ }^{1}$, Chris Bryan ${ }^{1}$, Martin Sparkes ${ }^{1}$, Fang Luo ${ }^{2}$ and William O’Neill ${ }^{1}$
}

The ability to manufacture coatings is critical to engineering design. Many components require the application of additional layers to enhance mechanical properties and protect against hostile environments. Supersonic laser deposition (SLD) is a novel coating method based on cold spray (CS) principles. In this technique, the deposition velocities can be significantly lower than those required for effective bonding in CS applications. The addition of laser heat energy permits a change in the thermodynamic experience of impacting particles, thereby offering a greater opportunity for efficient bonding at lower velocities as compared with the CS process. The work reported in this paper demonstrates the ability of the SLD process to deliver hardfacing materials to engineering surfaces. Stellite- 6 has been deposited on low-carbon steel tubes over a range of process parameters to establish the appropriate target power and traverse speeds for the coating formation. The coating properties and parameters were examined to determine the primary characteristics and grain structure size. Their morphology and performance were studied through optical microscopy, scanning electron microscope (SEM), X-ray diffraction, hardness measurements and wear testing. The results have shown that SLD is capable of depositing layers of Stellite-6, with properties that are superior to those of their conventionally manufactured counterparts.

Light: Science \& Applications (2012) 1, e10; doi:10.1038/lsa.2012.10; published online 11 May 2012

Keywords: cold spray; laser; supersonic laser deposition (SLD); Stellite; wear

\section{INTRODUCTION}

The current industrial demand for complex, high-quality engineering structures often requires the use of enhanced materials for the manufacturing of each individual component. In many applications, specific properties are only required locally, and are therefore achievable through the formation of coatings.

For the deposition of metallic layers, high-velocity oxygen-fuel and laser cladding (LC) $)^{1,2}$ are industrial technologies on which recent research efforts have concentrated. Each method differs in its working mechanism; however, both require the melting or partial melting of the feedstock material and a relatively high working temperature at the deposition site. Melting of the feedstock material often results in extensive oxidization, a change in the microstructure and in the formation of unwanted brittle phases during the re-solidification process. ${ }^{3,4}$ For example, Kuroda et al. ${ }^{5}$ described the high-velocity oxygen-fuel process as being inappropriate for the formation of corrosion protection titanium layers on large steel marine pillars because of the high oxygen content. In addition, when working temperatures are too high, distortion and cracking of the substrate material can occur. Such conditions are unacceptable when associated with the current industrial demand to produce high-quality components in a cost-efficient manner.

An alternative method is a solid-state deposition process known as cold spray (CS). ${ }^{6}$ In this technology, the feedstock material (in powder form) is not melted, but instead is accelerated at supersonic velocity by a carrier gas. The particles generate high-energy impacts when colliding against a substrate surface, each material and particle size is characterized by a minimum velocity for achieving deposition. ${ }^{7,8}$ Therefore, the use of helium at a high flow rate with gas heating is necessary for the formation of high-quality coatings made from strong, wear-resistant materials such as WC-Co. ${ }^{9-12}$ However, the high cost of helium makes the process expensive.

This paper presents experimental results related to the deposition of a C-Co-Cr hardfacing alloy (the commercial name is Stellite-6) onto steel substrates using an innovative process under development at the University of Cambridge and known as supersonic laser deposition (SLD). The vast majority of Stellite-6 deposits are currently manufactured via LC or arc welding; ${ }^{13,14}$ however, disadvantages such as a solidified microstructure due to the deposition of molten material are unavoidable. The SLD process has the potential to overcome the drawbacks of current technologies and has already been effectively applied to the deposition of titanium onto steel substrates. ${ }^{15}$ In this technique, the disadvantage of nitrogen as a carrier gas (with a low particle velocity) is compensated by the implementation of a laser source to illuminate the coating location. The optimized process parameters are presented along with a coating analysis and the initial results on the wear performance of the deposits.

${ }^{1}$ Institute for Manufacturing, Department of Engineering, University of Cambridge, Cambridge CB3 OFS, UKand ${ }^{2}$ College of Zhijiang, Zhejiang University of Technology, Hangzhou 310024, China

Correspondence: Dr W O'Neill, Institute for Manufacturing, Department of Engineering, University of Cambridge, Cambridge CB3 OFS, UK

E-mail:wo207@eng.cam.ac.uk

Received: 15 December 2011; Revised: 9 March 2012; Accepted: 2 April 2012 


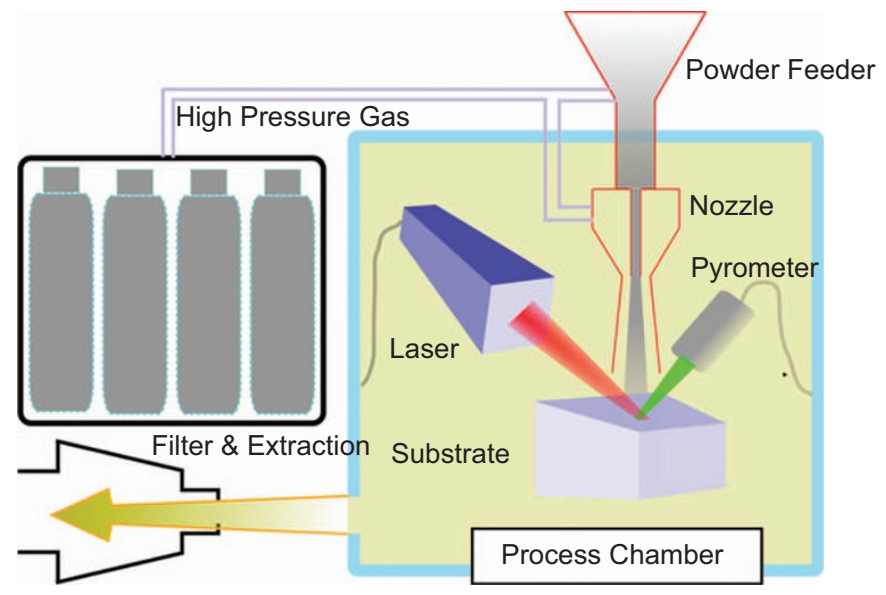

Figure 1 Supersonic laser deposition (SLD) process schematics.

\section{THE SLD PROCESS}

The SLD technology evolved from a successful preliminary study by Bray et al. ${ }^{16,17}$ on the effect of substrate softening on coating formation through the application of a 1-kW laser source at the deposition site.

The SLD process is similar in its mechanisms to CS; its schematics are shown in Figure 1. The metal powder, delivered from a highpressure feeder (Praxair 1264HP; Praxair Inc., Danbury, CT, USA), is accelerated to supersonic velocity through a carrier gas (nitrogen) within a converging-diverging supersonic nozzle. Various nozzle geometries can be implemented; the design is optimized for the acceleration of a specific powder material and size. The maximum allowable nozzle inlet pressure is 30 bar in the current system, yielding to a particle impact velocity within the 400-900 $\mathrm{m} \mathrm{s}^{-1}$ range depending on size and type of material. Threshold levels can be further increased with a gas heater (CGT kinetics 3000) to raise the gas temperature (500 ${ }^{\circ} \mathrm{C}$ max.) in the nozzle inlet, thus to increase its exit velocity. Examples of experimental measurements of achievable particle speeds with a similar spray system are reported in the literature. ${ }^{16}$ This study includes a comparison of the numerical results using a computational fluid dynamic analysis that demonstrates a close agreement between the two techniques.

As shown in Figure 1, the deposition zone is illuminated by a laser beam (4-kW maximum power, fiber laser, IPG) to soften (not melt) the substrate material and to reduce the yield stresses, thereby enabling the coating to form without needing to accelerate the powders up to the CS velocity. Thus, the deposition of high-strength materials is possible in a cost-efficient manner using nitrogen as the carrier gas. The nitrogen gas is supplied by multiple-cylinder pallets. After processing, it is removed from the working chamber through an extraction system.

Figure 2 shows the process work zone and the spatial arrangement of the main components: the laser head, the supersonic nozzle, the infrared pyrometer (two-color) and the spindle. The infrared pyrometer can be used to monitor the temperature at a spot on the coating and to maintain it at a set value through a PID closed-loop control with the laser. The spindle is implemented in the system to allow the coating of tubes.

\section{SLD OF STELLITE-6}

Stellite- 6 properties and applications

Stellite- 6 is a cobalt-based alloy consisting of complex carbides in a matrix. Its chemical composition is shown in Table 1. It is resistant to

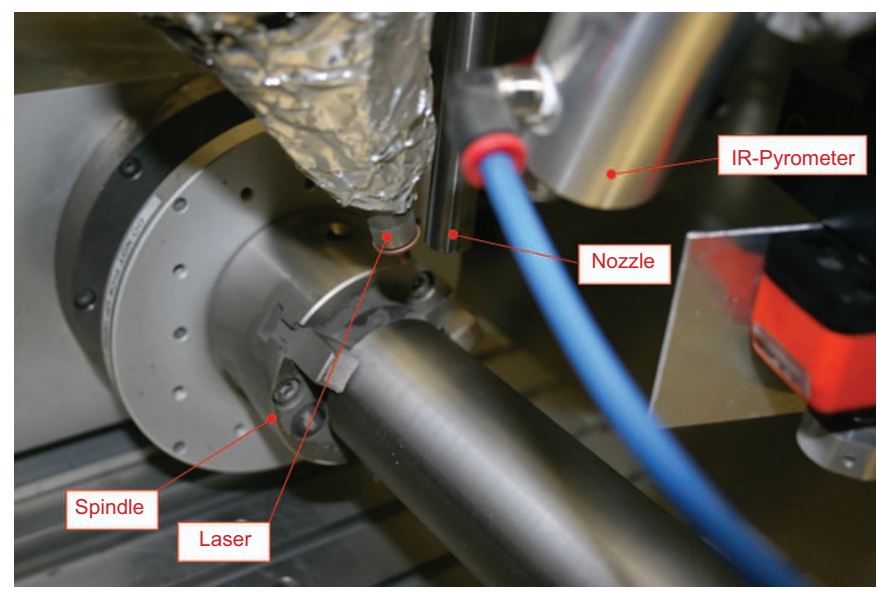

Figure 2 Supersonic laser deposition (SLD) processing work zone. IR = Infra-Red.

wear, galling and corrosion and retains these properties at high temperatures owing primarily to the characteristics inherent in the hard carbide phase dispersed in the Co-Cr alloy matrix. Further insights into the wear behavior of Stellite- 6 were recently provided by Wood et al. ${ }^{19}$ It is regarded as the industry standard for general-purpose wear resistance against many forms of mechanical and chemical degradation over a wide temperature range (retaining a reasonable level of hardness at high temperatures) and has good resistance to impact and cavitation erosion. Stellite- 6 is suited to a variety of hardfacing processes and can be machined with carbide tooling. Uses include valve seats and gates, pump shafts and bearings, erosion shields, rolling couples and the repair of corroded steam turbine blades.

\section{Coating manufacturing and characteristics}

The SLD process was used to produce Stellite- 6 coatings on lowcarbon steel substrates (43C) in the form of tubes. The tubes measured $50 \mathrm{~mm}$ in external diameter with a wall thickness of $3 \mathrm{~mm}$. Commercial spherical Stellite- 6 powder, ${ }^{18}-45 \mu \mathrm{m}$ in size, was used. The spraying process was carried out with nitrogen at an inlet pressure of 30 bar, heated to $500{ }^{\circ} \mathrm{C}$ to maximize the gas jet speed at the nozzle exit. The supersonic nozzle employed for the experiments had a restriction cross-sectional diameter of $2.7 \mathrm{~mm}$, an overall length of $200 \mathrm{~mm}$, and was manufactured in WC to minimize the powder erosion effect on the internal profile. A computational fluid dynamic model of the supersonic nozzle developed with ANSYS-Fluent 12.1 revealed a maximum carrier gas velocity of approximately $1000 \mathrm{~m} \mathrm{~s}^{-1}$ corresponding to the exit cross-section. The acceleration of the Stellite- 6 particles within the carrier gas was simulated through the discrete phase model algorithm (one-way coupling), and the highmach-number drag law. ${ }^{20}$ The computational results yielded a maximum velocity of nearly $640 \mathrm{~m} \mathrm{~s}^{-1}$ for a $30-\mu \mathrm{m}$ particle diameter, which corresponds to the average size in the commercial feedstock. This is well below the theoretical minimum deposition velocity for this type of material $\left(775 \mathrm{~m} \mathrm{~s}^{-1}\right)$ calculated using the formula published by Assadi et al. ${ }^{8}$ Experiments confirmed that coatings could not form

Table 1 Stellite-6 chemical composition (wt-\%), hardness and melting temperature

\begin{tabular}{lllllll}
\hline $\mathrm{Co}$ & $\mathrm{Cr}$ & $\mathrm{C}$ & $\mathrm{W}$ & $\mathrm{Ni}, \mathrm{Fe}, \mathrm{Si}, \mathrm{Mn}, \mathrm{Mo}$ & Hardness $(\mathrm{HV})$ & Melt range $\left({ }^{\circ} \mathrm{C}\right)$ \\
\hline Base & 28.5 & 1.2 & 4.6 & $<2$ & $380-490$ & $1285-1410$ \\
\hline
\end{tabular}




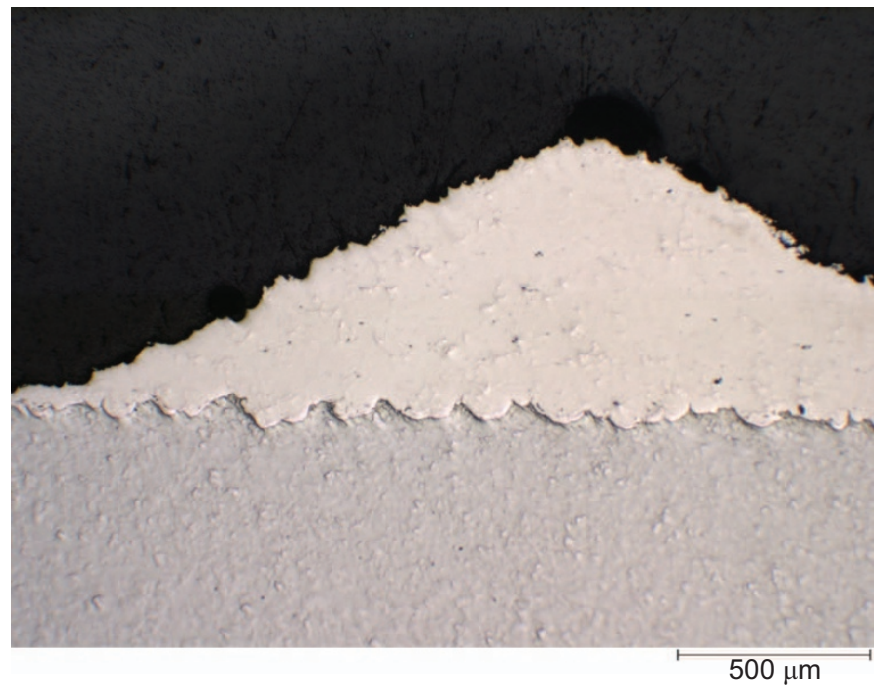

Figure 3 Typical Stellite- 6 coating track cross-section on steel by supersonic laser deposition (SLD).

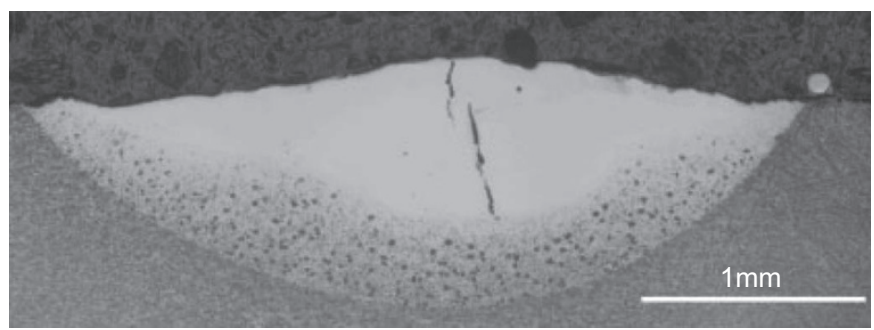

Figure 4 Stellite- 6 coating track cross-section by laser cladding. ${ }^{21}$

under these processing conditions with nitrogen as the carrier gas in unassisted CS.

The coating process was investigated with a selection of operating parameters to identify the optimum settings. The laser power was changed with each trial within the range of $1.2-3 \mathrm{~kW}$ and was tested at different substrate transverse speeds, i.e., the linear velocity at the outer circumference of the tube. The effect of the process powder feed rate on the deposition characteristics was also investigated.

Figure 3, obtained with an optical microscope, shows a cross-section of a typical Stellite- 6 single track produced via SLD. The coating was cross-sectioned and ground flat with $\mathrm{SiC}$ grit paper. The final polished state was achieved with the sequential application of a 9$\mu \mathrm{m}$ diamond suspension, a 3- $\mu \mathrm{m}$ diamond suspension and a $0.04-$ $\mu \mathrm{m}$ colloidal silica suspension. The figure suggests that the deposit is characterized by a relatively low porosity and a negligible heat-affected zone on the substrate. Erosion or cracking of the steel substrate and coating did not occur.
In contrast, Figure 4 shows the cross-section of a Stellite- 6 coating produced by laser cladding, requiring the complete melting of the feedstock material. ${ }^{21}$ The heat-affected zone is large, approaching $1 \mathrm{~mm}$ in depth. In this case, distortion of the work piece is likely to occur; cracking of the coating can be caused by high stresses that can form through differential contraction following the clad formation. The generation of dilution layers is inevitable and can result in poor coating properties and hardness. ${ }^{13}$ As a solid-state deposition process, SLD has the potential to overcome to these difficulties and disadvantages.

Single tracks can simply be overlapped to form a wider coating as the micrograph cross-section of a flat steel substrate in Figure 5 illustrates. No cracks were observed in either the substrate or the coating.

It was possible to efficiently deposit Stellite- 6 at transverse speed levels up to $40 \mathrm{~mm} \mathrm{~s}^{-1}$ for a coating build rate of approximately $2.2 \mathrm{~kg} \mathrm{~h}^{-1}$, using 3-kW laser power. Under such processing conditions, the porosity of the deposited layer was measured (optically) at $<1 \%$, while the microhardness approached $610 \mathrm{HV}$ (as measured with a commercial Mitutoyo Vickers testing machine), higher than that of the material in the bulk form as indicated in Table 1. The adhesion strength of the coating was also measured through a pull-off experiment in which a metallic dolly ( $8-\mathrm{mm}$ diameter) is glued onto the outer surface of the coating with an epoxy resin. The pressure required to pull out the dolly yields the bond strength. However, in this case, the resin failed at $62.4 \mathrm{MPa}$ leading to the conclusion that the actual bond strength between the coating and the substrate is considerably higher.

\section{Coating microstructural analysis and performance}

Figure 6 shows a micrograph cross-section (optical microscope) of a Stellite- 6 coating chemically etched with aqua regia. The deposit was

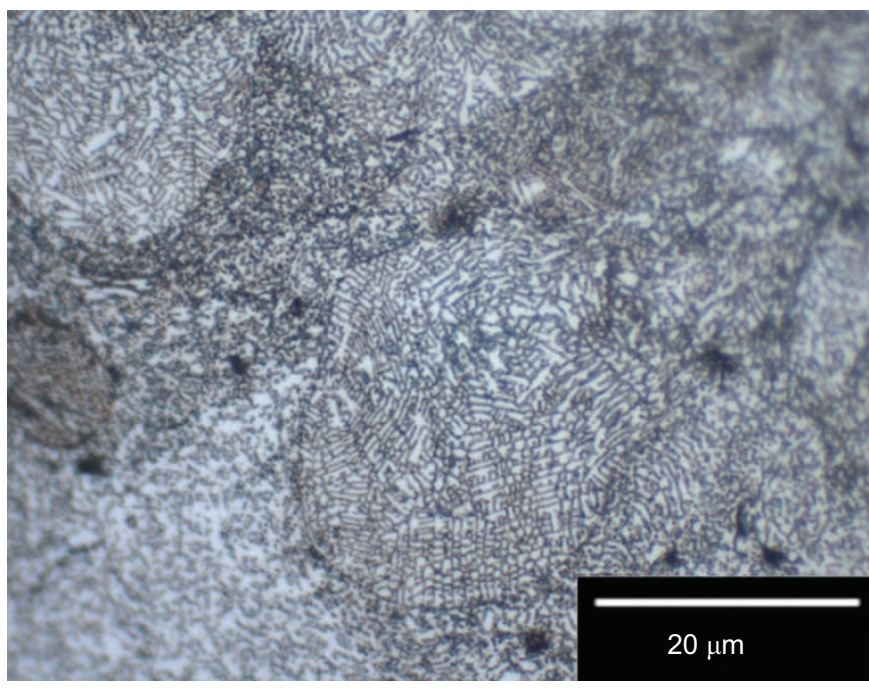

Figure 6 Etched Stellite- 6 coating track cross-section (optical microscope).

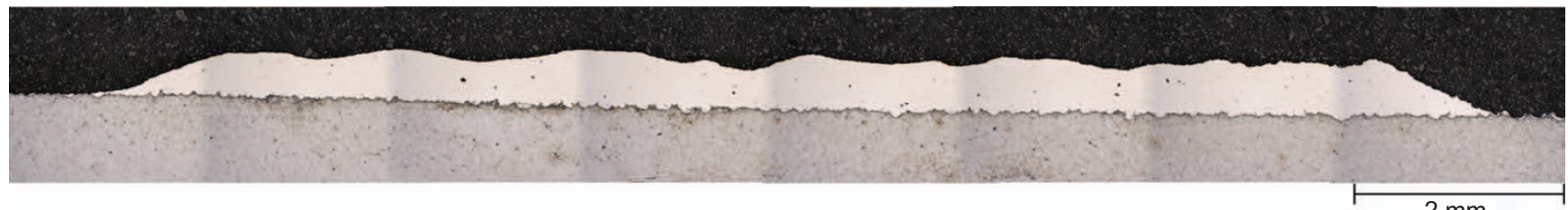

Figure 5 Wide Stellite- 6 coating on steel. 


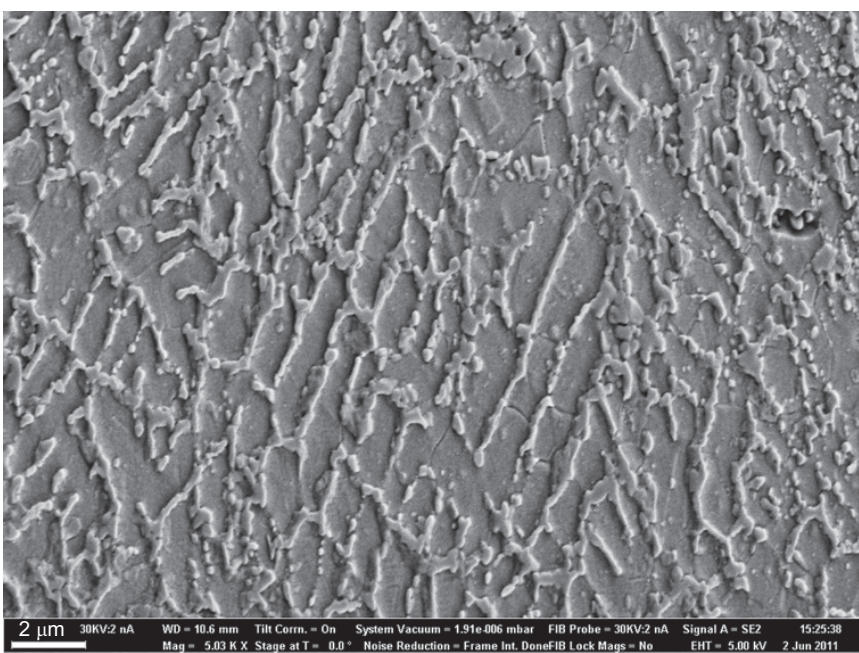

Figure 7 Etched Stellite- 6 coating cross-sectional image within a single particle (scanning electron microscope(SEM)).

manufactured on a steel tube substrate with $3-\mathrm{kW}$ laser power and a transverse speed of $40 \mathrm{~mm} \mathrm{~s}^{-1}$. The figure clearly indicates that particles are plastically deformed because of the high-energy impacts on the substrate surface. Such behavior is also typical in CS. As particle boundaries are clearly visible, one can confirm that no melting of the coating occurred during the deposition process. The grain structure and its overall size, measuring less than $1 \mu \mathrm{m}$ in most locations, can be observed within each deformed particle in Figure 6.

The grain of the Stellite- 6 deposit is more clearly observed in the etched scanning electron microscope (SEM) images shown in Figure 7. The location of the carbide phases, more resistant to the corrosive action of the etching acid, could be highlighted. Figure 8 confirms that the size is relatively small, in the $200-400 \mathrm{~nm}$ range.

Figure 9 shows an SEM image of a single Stellite- 6 particle prior to the spraying process. The grain structure is visible and similar in size to the coating in Figure 7 confirming excellent structural integrity and preservation of the material from the pre- to the post-processing configuration.

For comparison, Figure 10 provides the grain structure of a laserclad Stellite-6 coating. Dendrites similar to those from SLD are

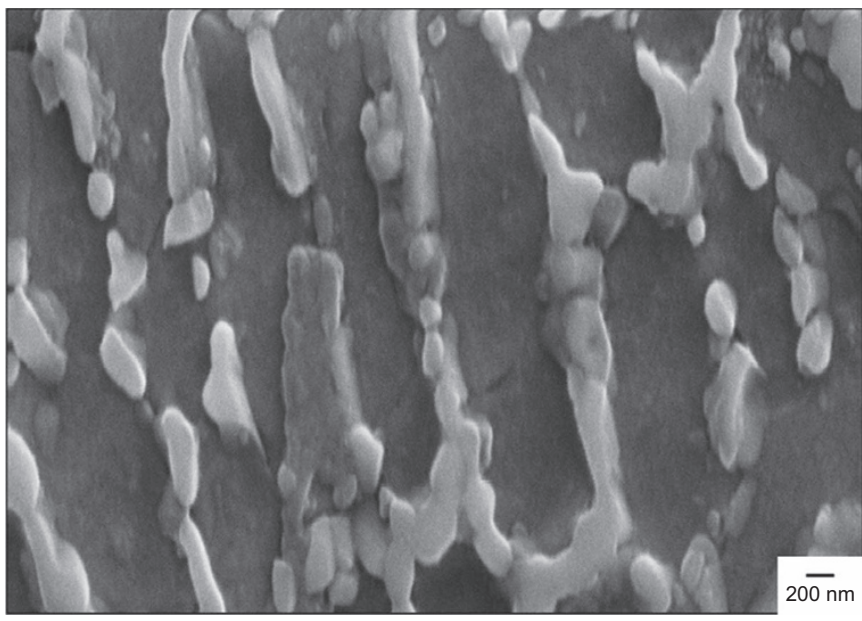

Figure 8 Etched Stellite- 6 coating cross-sectional image (close-up) within a single particle by a scanning electron microscope (SEM) analysis.

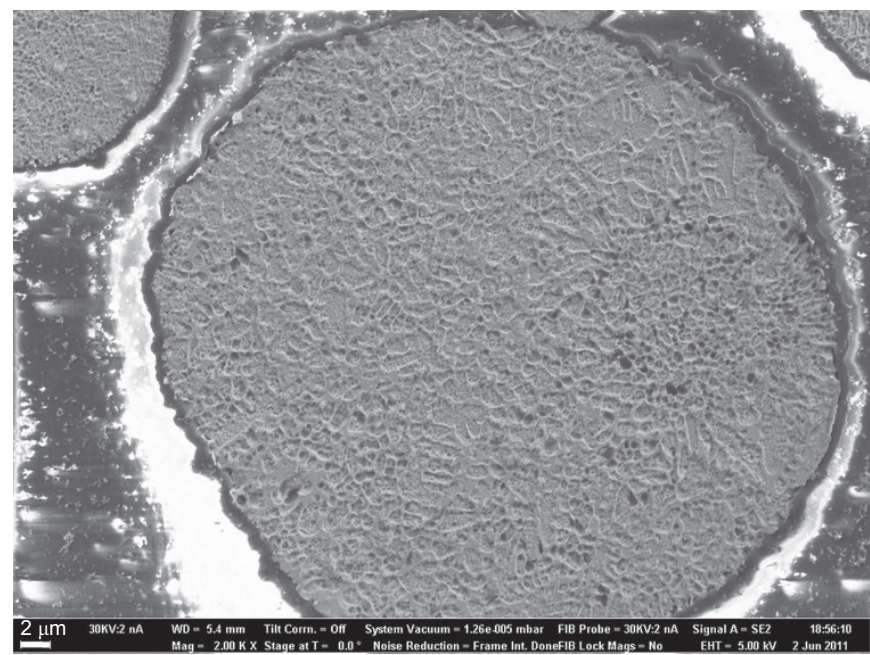

Figure 9 Etched single Stellite-6 particle cross-section prior to the spraying process (scanning electron microscope (SEM)).

observed; however, the overall size is considerably larger and reported to be approximately $1.1 \mu \mathrm{m} .{ }^{22}$ When the coating is welded, the SEM images reveal a grain size of over $20 \mu \mathrm{m} .^{14}$

One major drawback of metal deposition techniques based upon the complete or partial melting of the feedstock material and substrate is the formation of undesirable phases during the solidification process. X-ray diffraction analysis was therefore carried out in both the Stellite-6 powder and the SLD coating to examine the potential difference between the two. The X-ray diffraction of the coating was executed on the outer layer. The results are plotted in Figure 11. The peaks corresponding to specific phases have similar outcomes in both the powder and the coating, confirming that this material can retain its original structure through SLD processing. However, some differences were observed; additional phases appear in the coating, but not in the powder. The predominant peak is likely associated with the $\mathrm{CrO}$ phase, though a more detailed analysis is necessary to confirm this result.

To assess the mechanical performance of the coatings, a wear test was executed using a commercial rotational wear-testing machine

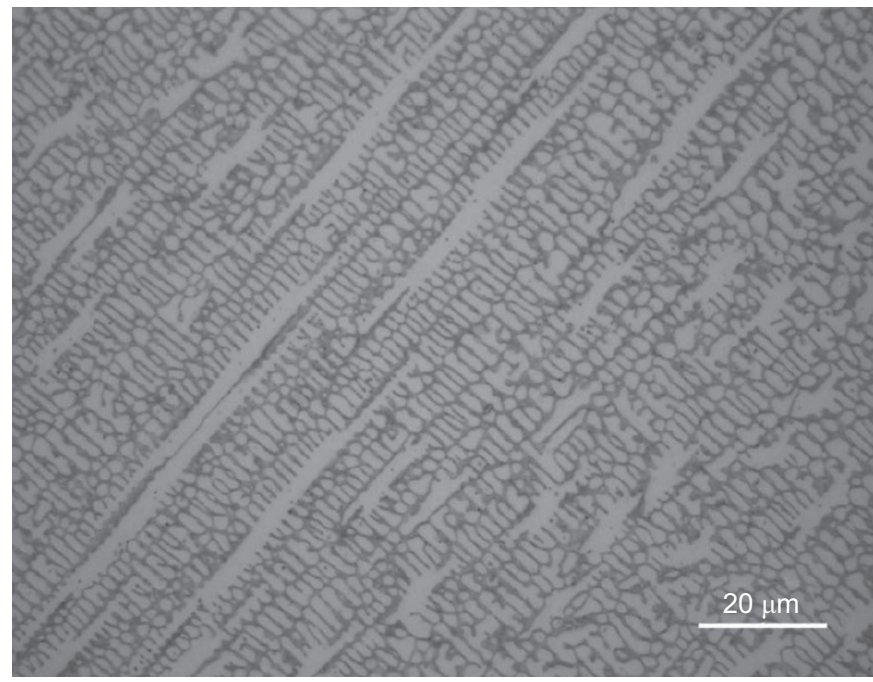

Figure 10 Stellite- 6 coating by laser cladding, grain structure visualization. ${ }^{22}$ 


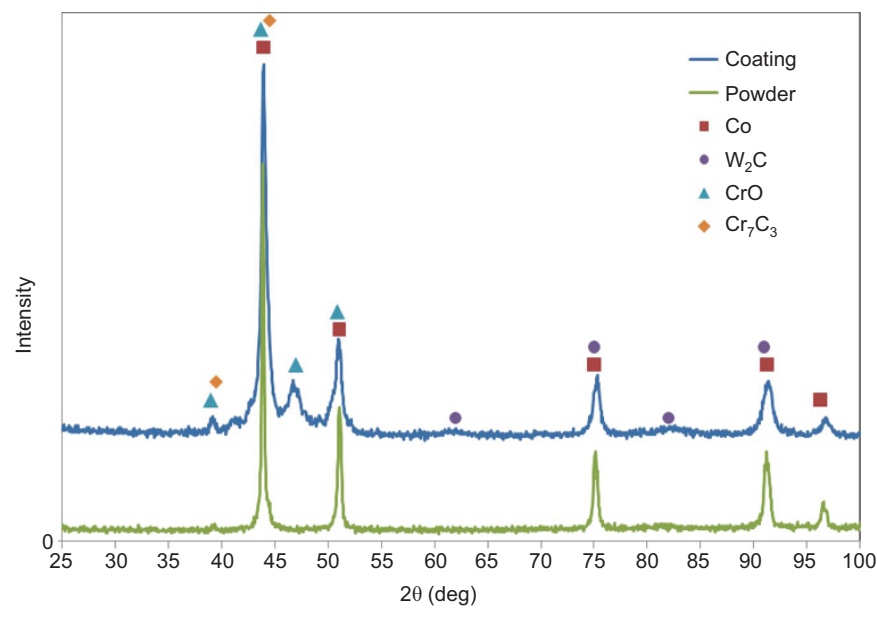

Figure 11 X-ray diffraction (XRD) analysis of Stellite-6 powder and coating with supersonic laser deposition (SLD).

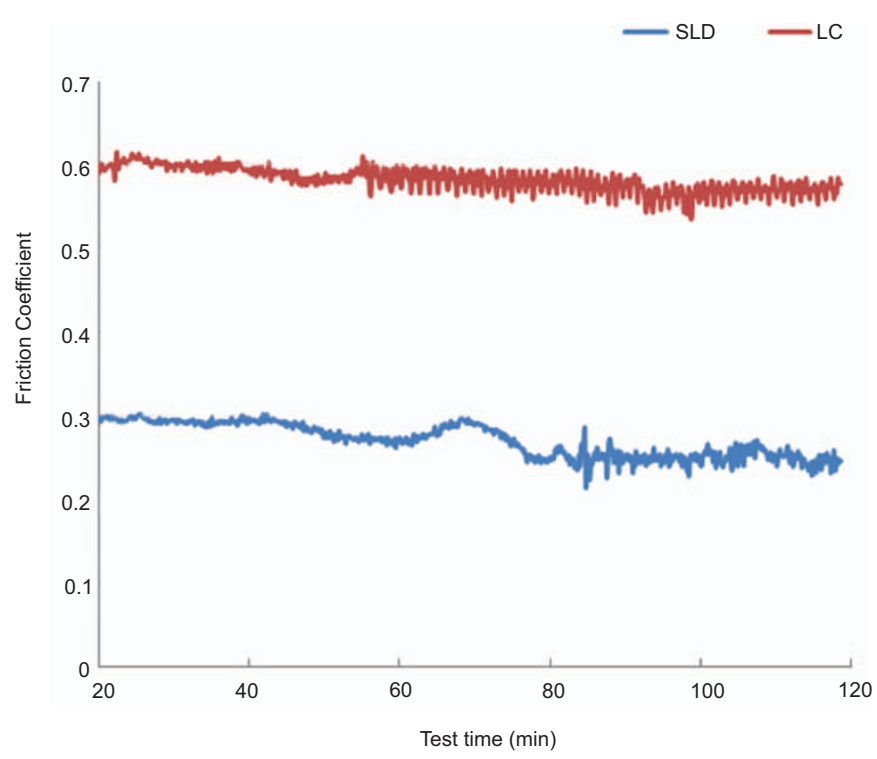

Figure 12 Experimental friction coefficient measurements of Stellite- 6 coatings by supersonic laser deposition (SLD) and laser cladding.

with a spherical $\mathrm{Si}_{3} \mathrm{~N}_{4}$ ceramic tool. A $200 \mathrm{~g}$ pre-load was applied to the sample, and the test was carried out for approximately $120 \mathrm{~min}$ at a tool speed of $800 \mathrm{rpm}$. The same test was performed on a Stellite- 6 sample produced with LC using $1.8-\mathrm{kW}$ laser power at the transverse speed of $8.3 \mathrm{~mm} \mathrm{~s}^{-1}$. Figure 12 shows the measured friction coefficient for the two deposition techniques during the wear test over the time after $20 \mathrm{~min}$ and before the end of the experiment. The Stellite- 6 deposited by SLD performed better than its laser-clad counterpart, having a considerably lower friction coefficient and minor fluctuations during the test. Therefore, these initial results indicate that the SLD-processed Stellite- 6 has the potential for a higher level of performance and endurance. The primary explanations for these results are directly related to the observed structure of the SLD coating; nanocrystalline coatings are known to possess unique chemical, physical and mechanical properties (superior hardness and strength) with the potential for new technological applications as reported by Tjong and Chen. ${ }^{23}$

\section{CONCLUSIONS}

The SLD process was introduced. This coating method is similar in working principle to the CS technique; however, deposition is possible without accelerating the metal particles to their full critical velocity. SLD was applied to the hardfacing of low-carbon steel tubes with Stellite-6. The deposition parameter window was investigated; it was possible to form deposits on the substrate at the transverse speed of $40 \mathrm{~mm} \mathrm{~s}^{-1}$ with the $3-\mathrm{kW}$ laser power, resulting in a $2.2 \mathrm{~kg} \mathrm{~h}^{-1}$ build rate. SLD coatings of Stellite- 6 exhibited a crack-free structure, low porosity and excellent bond strength with the substrate. These properties were achieved without melting the feedstock material or causing permanent damage and distortion to the substrate. The coating grain size was found to be submicron (200-400 nm), resulting in an improved wear-test performance versus laser cladding coatings. An initial study found the measured friction coefficient of a Stellite-6 layer produced with SLD to be approximately 2.4 times less than that with laser cladding.

\section{ACKNOWLEDGMENTS}

The authors express their gratitude to the IKC UPS² (UK) research program, EPSRC (UK), Laser Fusion Technologies Ltd. and IPG Photonics for their technical and financial support. Also, to the Maney Publishing group for the assistance in the publication of this article.

1 Sobolev VV, Guilemany J, Guilemany JM. HVOF Spraying: Theory and Applications. London: The Institute of Materials; 1997.

2 Toyserkani E, Khajepour A, Corbin SF. Laser Cladding. Boca Raton, FL: CRC Press; 2004.

3 Guilemany JM, de Paco JM, Nutting J, Miguel JR. Characterization of the $\mathrm{W}_{2} \mathrm{C}$ phase formed during the high velocity oxygen fuel spraying of a WC +12 Pct Co powder. Metall Mater Trans A 1999; 30A: 1913-1921.

4 Verdon C, Karimi A, Martin JL. A study of high velocity oxy-fuel thermally sprayed tungsten carbide based coatings. Part 1: Microstructures. Mater Sci Eng A 1998; 246: 11-24.

5 Kuroda S, Watanabe M, Kim K, Katanoda H. Current status and future prospects on warm spray technology. J Therm Spray Technol 2011; 20: 653-676.

6 Champagne VK. The Cold Spray Materials Deposition Process: Fundamentals and Applications. Cambridge: Woodhead Publishing; 2007.

7 Schmidt T, Assadi H, Gartner F, Richter H, Stoltenhoff T et al. From particle acceleration to impact and bonding in cold spraying, J Therm Spray Technol 2009; 18: 794-808

8 Assadi H, Gartner F, Stoltenhoff T, Kreye H. Bonding mechanism in cold gas spraying. Acta Mater 2003; 51: 4379-4394.

9 Ang AS, Berndt CC, Cheang P. Deposition effect of WC particle size on cold sprayed WC-Co coatings. Surf Coat Technol 2011; 205: 3260-3267.

$10 \mathrm{Kim} \mathrm{HJ}$, Leeb $\mathrm{CH}$, Hwanga SY. Fabrication of WC-Co coatings by cold spray deposition. Surf Coat Technol 2005; 191: 335-340.

11 Gao PH, Li CJ, Yang GJ, Li YG, Li CX. Influence of substrate hardness on deposition behaviour of single porous WC-12Co particle in cold spraying. Surf Coat Technol 2008; 203: 384-390.

12 Yandouzi M, Sansoucy E, Ajdelsztajn L, Jodoin B. WC-based cermet coatings produced by cold gas dynamic and pulsed gas dynamic spraying processes. Surf Coat Technol 2007; 202: 382-390.

13 Sun S, Durandet $Y$, Brandt M. Parametric investigation of pulsed Nd:YAG laser cladding of stellite- 6 on stainless steel. Surf Coat Technol 2005; 194: 225-231.

14 Gholipour A, Shamanian M, Ashrafizadeh F. Microstructure and wear behavior of stellite-6 cladding on 17-4 PH stainless steel. J Alloys Compd 2011; 509: 49054909.

15 Lupoi R, Sparkes M, Cockburn A, O’Neill W. High speed titanium coatings by supersonic laser deposition. Mater Lett 2011; 65: 3205-3207.

16 Bray M, Cockburn A, O'Neill W. The laser-assisted cold spray process and deposit characterization. Surf Coat Technol 2009; 203: 2851-2857.

17 Bray M, Cockburn A, Sparkes M, Lupoi R, O'Neill W. Supersonic laser deposition of $\mathrm{Ti}$ and Ti64 alloys. In: Proceedings of the 29th International Congress on Applications of Lasers and Electro-Optics 2010; 26-30 September Anaheim, CA, USA. pp435441.

18 Deloro Stellite-6 powder material data sheet, http://www.stellite.co.uk

19 Wood PD, Evans HE, Ponton CB. Investigation into the wear behavior of Stellite- 6 during rotation as an unlubricated bearing at $600{ }^{\circ} \mathrm{C}$. Tribol Int 2011; 44: 1589 1597 
20 ANSYS, Inc. ANSYS-Fluent 12.1 User Guide and Manual. Canonsburg, PA: ANSYS, Inc.; 2009.

21 Brandt M, Sun S, Alam N, Bendeich P, Bishop A. Laser cladding repair of turbine blades in power plants: from research to commercialization. Int Heat Treat Surf Eng 2009; 3: 105-114.

22 Sun S, Brandt M. Comparison between continuous wave and pulsed ND:YAG laser cladding of Stellite-6. In: Proceedings of the 23rd International Congress on Applications of Lasers and Electro-Optics 2004. 16-21 May San Francisco, CA, USA. Laser Institute of America: Orlando, FL, USA, 2004.

23 Tjong SC, Chen H. Nanocrystalline materials and coatings. Mater Sci Eng R 2004; 45: $1-88$.

(c) This work is licensed under a Creative Commons

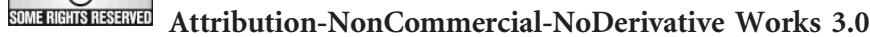
Unported License. To view a copy of this license, visit http:// creativecommons.org/licenses/by-nc-nd/3.0 